\title{
Desempenho agronômico de híbridos de sorgo granífero na safrinha em Jataí-GO
}

Agronomic performance of grain sorghum hybrids in off-season cultivation in Jataí, State of Goiás, Brazil

\author{
E. F. Almeida ${ }^{1}$; J. H. Mota ${ }^{1 *}$; C. B. Menezes ${ }^{2}$; J. E. Yuri ${ }^{3}$; G. M. Resende \\ ${ }^{1}$ Universidade Federal de Goiás - Regional Jataí, CEP 75801-615 - Jataí, GO, Brasil. \\ ${ }^{2}$ EMBRAPA Milho e Sorgo, CEP 35701-970, Sete Lagoas-MG, Brasil \\ ${ }^{3}$ EMBRAPA Semiárido, CEP 56302-970. Petrolina-PE, Brasil \\ *email do autorcorrespondente: hortenciomota@ufg.br
}

(Recebido em 18 de setembro de 2015; aceito em 17 de novembro de 2015)

\begin{abstract}
O objetivo deste estudo foi avaliar as características agronômicas de 25 híbridos de sorgo granífero cultivados no período da safrinha em Jataí-GO. Foi instalado um experimento em blocos casualizados com três repetições e avaliadas as seguintes características: número de dias entre a semeadura e o emborrachamento; número de dias da semeadura até o florescimento; altura de plantas; comprimento da panícula, peso de mil grãos e rendimento. Verificou-se que os híbridos não diferenciaram entre si quanto ao emborrachamento, florescimento e altura de plantas. Para o tamanho de panícula os híbridos que se destacaram foram: 1167017, 1170017 e 1169074. Os híbridos DKB550, 1237030, 1170017, 1167017 e 1099044 apresentaram os maiores pesos de mil grãos. Em relação ao rendimento, os híbridos 1238020 , 1169092, 1G244, 843009, 1236020, 1099034, 1167053, BRS330, 1105661, 1099044, 1105653, 1167017, 729033 e 1167093 apresentaram maiores rendimentos, o que pode estar ligado à maior adaptação dos materiais às condições edafoclimáticas da região.

Palavras-chave: Sorghum bicolor L. Moench, produtividade, cultivares.
\end{abstract}

The aim of this study was to evaluate the agronomic characteristics of 25 hybrids of sorghum for double cropping in Jataí, State of Goiás, Brazil. An experiment was installed in a randomized block design with three replications. The characteristics evaluated were: number of days between sowing and booting; number of days between sowing and flowering; plant height; panicle length, thousand grain weight and yield. It was found that the hybrids did not differ regarding the boot stage, flowering and plant height. For the panicle length, the hybrids 1167017, 1170017 and 1169074 stood out. The hybrids DKB550, 1237030, 1170017, 1167017 and 1099044 showed higher thousand grain weight. For yield, the hybrids 1238020 , 1169092, 1G244, 843009, 1236020, 1099034, 1167053, BRS330, 1105661, 1099044, 1105653, 1167017, 729033 and 1167093 showed higher yields, which can be linked to higher soil and climatic adaptation.

Keywords: Sorghum bicolor L. Moench, yield, cultivars.

\section{INTRODUÇÃO}

O sorgo (Sorghum bicolor L. Moench) pertencente à família Poaceae é um cereal de origem africana e asiática, introduzido no Brasil no início do século XX, e que vem sendo utilizado tanto para produção de grãos como para produção de forragem [1]. É uma cultura que conseguiu se adaptar bem a algumas regiões brasileiras, tornando-se o quinto cereal de maior produção no mundo e o quarto no ranking de produção do país [2]. A área cultivada com sorgo no Brasil na safrinha 2014/2015 foi de 721 mil hectares com produtividade média de $2.710 \mathrm{~kg} \mathrm{ha}^{-1}$ [3].

É utilizado em todas as partes do mundo na alimentação humana e animal [4], apresentando valor nutritivo entre 90 e 95\%, valor este similar ao milho [5], além disso, o sorgo e o milho podem ser considerados equivalentes quanto aos teores de minerais e vitaminas [6].

No Brasil, são cultivados quatro tipos de sorgo: granífero, forrageiro, sacarino e vassoura, sendo que o tipo granífero, possui maior área cultivada, por ser o mais viável economicamente [7, 8].

O sorgo granífero adapta-se bem em diversos ambientes, principalmente naqueles com condições de deficiência hídrica [9]. Essa característica facilitou a expansão do cereal em regiões 
com distribuição irregular de chuvas e, até mesmo, seu uso em sucessão a culturas de verão [10]. Para produzir grãos, o sorgo requer cerca de $25 \mathrm{~mm}$ de chuva após o plantio, $250 \mathrm{~mm}$ durante o crescimento e 25 a $50 \mathrm{~mm}$ durante a maturidade [11].

O sorgo granífero tem se tornado mais uma opção de plantio na safrinha do Centro-Oeste, substituindo o milho, visto que seu custo é estimado em 20 a $30 \%$ inferior ao da cultura do milho [10], tornando o cereal uma alternativa viável e econômica para o produtor.

Outra característica da cultura é que a mesma pode ser mecanizada, maximizando a eficiência das operações e, também, apresenta uma maior amplitude de época da semeadura, possibilitando flexibilidade na implantação da cultura em safrinha [12]. Destaca-se, também, o auxílio da palhada do sorgo no controle de ervas daninhas [13], agindo como uma barreira física e alelopática, o que pode proporcionar menor infestação de plantas daninhas, na safra seguinte.

As cultivares graníferas, de sorgo presentes no mercado, diferem entre si, quanto ao rendimento de grãos, ciclo vegetativo e outras características agronômicas [14]. A escolha da cultivar adequada as características de cada região e o manejo correto da cultura são fatores cruciais para o aumento na produtividade.

O objetivo deste trabalho foi avaliar características agronômicas de 25 híbridos de sorgo granífero, no período de safrinha em sucessão a cultura da soja, nas condições edafoclimáticas de Jataí-GO.

\section{MATERIAL E MÉTODOS}

O experimento foi conduzido na safrinha de 2014, entre os meses de março a junho, na área experimental da Universidade Federal de Goiás-Regional Jataí, localizada nas coordenadas $17^{\circ} 52^{\prime} 33^{\prime \prime}$ S e $51^{\circ} 43^{\prime} 17^{\prime}$ 'O, com altitude média de $789 \mathrm{~m}$.

O clima da região, segundo a classificação de Köppen, é do tipo Aw - tropical de savana e megatérmico com estações seca e chuvosa definidas. A temperatura média anual é de $23,7^{\circ} \mathrm{C}$ e a precipitação anual média de 1644,9 mm [15].

As variações médias de precipitação e temperatura do ar, registradas na Estação Meteorológica da Universidade Federal de Goiás -Regional Jataí, no período de condução do experimento são apresentadas na Figura 1. Essa estação se encontra em média $2 \mathrm{~km}$ do local onde o ensaio foi instalado. Durante o tempo de condução do experimento, a precipitação total foi de $328 \mathrm{~mm}$ e a temperatura teve variação de 9 a $33^{\circ} \mathrm{C}$.

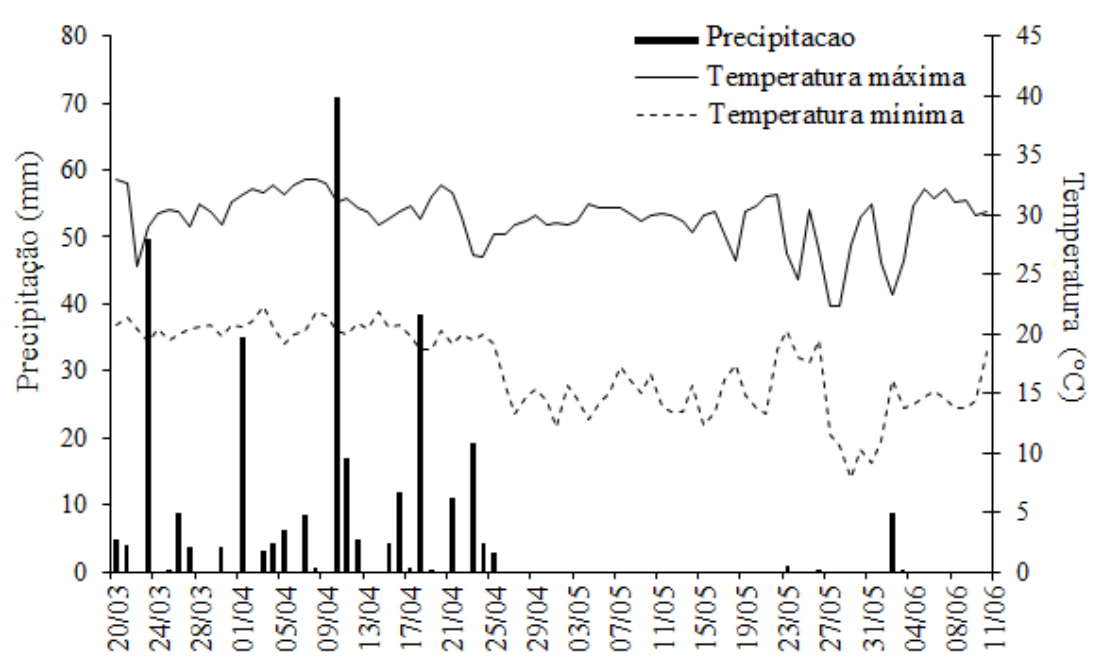

Figura 1: Precipitação pluviométrica $(\mathrm{mm})$ e temperaturas máxima e mínima $\left({ }^{\circ} \mathrm{C}\right)$ registradas no período de março a junho de 2014 em Jataí - GO (Fonte: [16]).

O solo predominante na área experimental é classificado como um Latossolo Vermelho distroférrico [17]. A amostragem do solo foi feita na camada de 0 a $20 \mathrm{~cm}$, as características químicas do solo utilizado foram: $\mathrm{pH}=5,83 ; \mathrm{P}=10,7 \mathrm{mg} \mathrm{dm}^{-3} ; \mathrm{K}=64 \mathrm{mg} \mathrm{dm}{ }^{-3} ; \mathrm{Ca}^{2+}=3,52$ cmolc $\mathrm{dm}^{-3} ; \mathrm{Mg}^{2+}=1,21 \mathrm{cmolc} \mathrm{dm}^{-3} ; \mathrm{Al}^{3+}=0,1 \mathrm{cmolc} \mathrm{dm}^{-3} ; \mathrm{H}+\mathrm{Al}=9,56 \mathrm{cmolc} \mathrm{dm}^{-3}$. 
A área onde o experimento foi instalado foi ocupada com o cultivo de soja na safra de verão, com sucessão do sorgo na safrinha, utilizando sempre o sistema de plantio direto.

$\mathrm{O}$ delineamento experimental adotado foi de blocos casualizados com 3 repetições. As parcelas foram compostas por 4 linhas de $5 \mathrm{~m}$, espaçadas $0,45 \mathrm{~m}$ entre si. A área útil para avaliação das parcelas e coleta de dados foi obtida utilizando as duas fileiras centrais.

Foram avaliado 25 híbridos de sorgo granífero, sendo 22 híbridos simples, pré-comerciais, oriundos do Núcleo de Recursos Genéticos e Desenvolvimento de Cultivares da Embrapa Milho e Sorgo (1167093, 1105653, 1099034, 1167048, 1236011, 1099044, 1168092, 1237030, 1169074, 1096019, 0729033, 1167053, 0843009, 1168093, 1238020, 1236020, 1170017, 1105661, 1169054, 1169092, 1167017 e 1167092) e três híbridos comerciais (1G244, DKB 550 e BRS 330). Para garantir a homogeneidade dos espaçamentos utilizou-se a semeadora para tracejar as linhas de plantio, realizando o plantio manual, no dia 20 de março de 2014.

Na semeadura foram aplicados $310 \mathrm{~kg} \mathrm{ha}^{-1}$ do fertilizante 06-30-06 (N-P-K) e para adubação de cobertura $115 \mathrm{~kg} \mathrm{ha}^{-1}$ de uréia, 30 dias após o plantio. Para o controle de plantas daninhas, realizou-se aos 40 dias após a semeadura uma aplicação de $21 \mathrm{ha}^{-1}$ de glyphosate.

Realizou-se a colheita manual 115 dias após o plantio, retirando as panículas presentes na área útil das parcelas. As características avaliadas foram: dias entre a semeadura e o emborrachamento (emissão de panículas, em 50\% das plantas); florescimento (número de dias decorridos desde o plantio até a exteriorização do estame das panículas de $50 \%$ das plantas da unidade experimental); altura de plantas (altura média de 5 plantas, em metros, medidas do solo até o ápice da panícula); comprimento da panícula $(\mathrm{cm})$ : a mesma foi medida com auxilio de uma régua graduada, avaliando todo o seu comprimento; peso de mil grãos $(\mathrm{g})$ : panículas foram debulhadas e por meio de um contador eletrônico foram contados 2 amostras de mil grãos e pesados corrigindo-se a umidade para 13\%; rendimento de grãos: pesagem dos grãos, corrigindose a umidade para $13 \%$ e convertendo-se os dados para $\mathrm{tha}^{-1}$.

Os dados obtidos foram submetidos à análise de variância, com as médias comparadas pelo teste de Scott-Knott a 5\% de probabilidade.

\section{RESULTADOS E DISCUSSÃO}

Das características agronômicas analisadas, não houve diferenças significativas entre os híbridos para emborrachamento, florescimento e altura de plantas. Observou-se diferença significativa para as características tamanho de panícula, peso de mil grãos e rendimento (Tabela 1). 
Tabela 1: Valores médios do número de dias até o emborrachamento (Emb.) e até o florescimento (Flor.), comprimento de panículas (Pan.), altura de plantas (Alt.), peso de mil grãos (Peso) e rendimento de grãos (Rend.) de híbridos de sorgo cultivados na safrinha em Jataí-GO

\begin{tabular}{|c|c|c|c|c|c|c|}
\hline Híbrido & $\begin{array}{l}\text { Emb. } \\
\text { (dias) }\end{array}$ & $\begin{array}{l}\text { Flor. } \\
\text { (dias) }\end{array}$ & $\begin{array}{l}\text { Pan. } \\
\text { (cm) }\end{array}$ & $\begin{array}{l}\text { Alt. } \\
\text { (m) }\end{array}$ & $\begin{array}{l}\text { Peso } \\
\text { (g) }\end{array}$ & $\begin{array}{l}\text { Rend. } \\
\text { (t ha-1) }\end{array}$ \\
\hline 1096019 & $50 \mathrm{a}$ & $57 \mathrm{a}$ & $24,50 \mathrm{c}$ & $1,40 \mathrm{a}$ & $15,35 \mathrm{~b}$ & $2,97 \mathrm{~b}$ \\
\hline 1168093 & $52 \mathrm{a}$ & $63 a$ & $18,62 \mathrm{~d}$ & $1,24 \mathrm{a}$ & $16,14 b$ & $3,68 \mathrm{~b}$ \\
\hline 1170017 & $52 \mathrm{a}$ & $62 \mathrm{a}$ & $36,29 \mathrm{a}$ & $1,35 \mathrm{a}$ & $18,42 \mathrm{a}$ & $3,33 \mathrm{~b}$ \\
\hline 1169092 & $53 \mathrm{a}$ & $61 \mathrm{a}$ & $30,22 \mathrm{~b}$ & $1,38 \mathrm{a}$ & $16,03 \mathrm{~b}$ & $4,77 \mathrm{a}$ \\
\hline 1099044 & $53 \mathrm{a}$ & $61 \mathrm{a}$ & $21,30 \mathrm{~d}$ & $1,32 \mathrm{a}$ & $17,94 \mathrm{a}$ & $3,97 \mathrm{a}$ \\
\hline 1105653 & $53 \mathrm{a}$ & $62 \mathrm{a}$ & $29,25 \mathrm{~b}$ & $1,44 \mathrm{a}$ & $15,47 \mathrm{~b}$ & $3,97 \mathrm{a}$ \\
\hline 1105661 & $53 \mathrm{a}$ & $64 \mathrm{a}$ & $28,81 \mathrm{~b}$ & $1,47 \mathrm{a}$ & $16,43 \mathrm{~b}$ & $4,02 \mathrm{a}$ \\
\hline 1167017 & $53 \mathrm{a}$ & $63 \mathrm{a}$ & $38,65 \mathrm{a}$ & $1,33 \mathrm{a}$ & $18,35 \mathrm{a}$ & $3,89 \mathrm{a}$ \\
\hline 1169074 & $53 \mathrm{a}$ & $61 \mathrm{a}$ & $33,44 \mathrm{a}$ & $1,36 \mathrm{a}$ & $14,58 \mathrm{a}$ & $2,88 \mathrm{~b}$ \\
\hline $1 \mathrm{G} 244$ & $53 \mathrm{a}$ & $63 \mathrm{a}$ & $31,75 \mathrm{~b}$ & $1,28 \mathrm{a}$ & $14,79 \mathrm{a}$ & $4,70 \mathrm{a}$ \\
\hline 1167053 & $54 \mathrm{a}$ & $63 \mathrm{a}$ & $29,42 \mathrm{~b}$ & $1.39 \mathrm{a}$ & $16,31 \mathrm{~b}$ & $4,18 \mathrm{a}$ \\
\hline 1236020 & $54 \mathrm{a}$ & $63 \mathrm{a}$ & $31,68 \mathrm{~b}$ & $1,29 \mathrm{a}$ & $15,12 b$ & $4,24 \mathrm{a}$ \\
\hline BRS330 & $54 \mathrm{a}$ & $62 \mathrm{a}$ & $26,20 \mathrm{c}$ & $1,32 \mathrm{a}$ & $14,35 \mathrm{~b}$ & $4,03 \mathrm{a}$ \\
\hline 843009 & $54 \mathrm{a}$ & $63 \mathrm{a}$ & $28,12 \mathrm{~b}$ & $1,36 \mathrm{a}$ & $15,10 \mathrm{~b}$ & $4,33 \mathrm{a}$ \\
\hline 729033 & $54 \mathrm{a}$ & $64 \mathrm{a}$ & $21,81 \mathrm{~d}$ & $1,40 \mathrm{a}$ & $15,73 b$ & $3,82 \mathrm{a}$ \\
\hline 1236011 & $54 \mathrm{a}$ & $63 \mathrm{a}$ & $24,44 \mathrm{c}$ & $1,36 \mathrm{a}$ & $15,54 \mathrm{~b}$ & $3,07 \mathrm{~b}$ \\
\hline 1168092 & $54 \mathrm{a}$ & $64 \mathrm{a}$ & $16,04 \mathrm{~d}$ & $1,30 \mathrm{a}$ & $16,03 \mathrm{~b}$ & $3,27 \mathrm{~b}$ \\
\hline 1238020 & $54 \mathrm{a}$ & $63 \mathrm{a}$ & $30,30 \mathrm{~b}$ & $1,38 \mathrm{a}$ & $16,25 \mathrm{~b}$ & $4,77 \mathrm{a}$ \\
\hline 1167048 & $55 \mathrm{a}$ & $64 \mathrm{a}$ & $29,93 \mathrm{~b}$ & $1,33 \mathrm{a}$ & $15,11 b$ & $3,52 \mathrm{~b}$ \\
\hline 1167093 & $55 \mathrm{a}$ & $66 \mathrm{a}$ & $20,48 \mathrm{~d}$ & $1,20 \mathrm{a}$ & $15,97 \mathrm{~b}$ & $3,77 \mathrm{a}$ \\
\hline 1099034 & $55 \mathrm{a}$ & $62 \mathrm{a}$ & $22,93 \mathrm{c}$ & $1,35 \mathrm{a}$ & $16,67 \mathrm{~b}$ & $4,23 \mathrm{a}$ \\
\hline 1237030 & $55 \mathrm{a}$ & $64 \mathrm{a}$ & $26,02 \mathrm{c}$ & $1,27 \mathrm{a}$ & $18,95 \mathrm{a}$ & $2,82 \mathrm{~b}$ \\
\hline 1169054 & $55 \mathrm{a}$ & $59 \mathrm{a}$ & $22,94 \mathrm{c}$ & $1,34 \mathrm{a}$ & $14,38 \mathrm{~b}$ & $3,32 \mathrm{~b}$ \\
\hline 1167092 & $57 \mathrm{a}$ & $66 \mathrm{a}$ & $17,50 \mathrm{~d}$ & $1,20 \mathrm{a}$ & $15,54 \mathrm{~b}$ & $3,59 \mathrm{~b}$ \\
\hline DKB550 & $57 \mathrm{a}$ & $65 \mathrm{a}$ & $26,68 \mathrm{c}$ & $1,26 \mathrm{a}$ & $19,08 \mathrm{a}$ & $3,43 \mathrm{~b}$ \\
\hline Média & 54 & 68 & 26,69 & 1,33 & 16,02 & 3,78 \\
\hline CV \% & 4,13 & 3,96 & 13,35 & 11,19 & 11,60 & 15,68 \\
\hline
\end{tabular}

Médias seguidas por mesma letra não diferem entre si pelo teste de Scott Knott $(\alpha=0,05)$.

Para a característica emborrachamento, verificou-se que não houve diferença significativa entre os híbridos, e os mesmos apresentaram início do emborrachamento 54 dias após a semeadura. Este comportamento pode estar relacionado com as condições climáticas favoráveis ao cultivo do sorgo na safrinha do sudoeste goiano. Belvilaqua (2013) [18] também não observou diferença significativa no emborrachamento quando foram analisados diferentes híbridos na safrinha 2013 em Jataí-GO. Ressalta-se que esta característica é imprescindível para a qualidade e segurança do cultivo de sorgo na safra de inverno nas regiões, pois com emborrachamento mais rápido, o florescimento será adiantado, tornando o híbrido mais precoce, minimizando assim riscos causados por um provável veranico. A colheita antecipada na época da safrinha permite maior flexibilidade nas negociações dos grãos, proporcionando maior lucratividade [14].

Considerando o período de florescimento das plantas de sorgo, os 25 híbridos avaliados não diferenciaram estatisticamente, ambos floresceram em média 68 dias após o plantio. Essa semelhança de média em dias para o florescimento pode-se dar pelo melhoramento vegetal feito pela melhorista em seus híbridos, o qual procurou a melhor adaptabilidade dos cultivares para diferentes regiões. Resultado diferente foi obtido por Almeida Filho et al. (2014) [19], os quais analisaram diferentes híbridos em diferentes regiões do Brasil, e obtiveram uma variabilidade de dias do plantio até o florescimento de 70,3 a 51,33 dias, sendo que nas regiões de Montividiu-GO e Rio Verde-GO obtiveram médias de 67 e 56 dias, respectivamente.

Heckler (2002) [20] observou a variação de 62 a 79 dias para o florescimento de cultivares de sorgo cultivadas na região Centro-Oeste, mostrando que os híbridos avaliados no presente trabalho mantiveram uma média de florescimento dentro dos padrões para a região e um ciclo de período intermediário comparando com os demais trabalhos. 
É importante que existam cultivares com diferentes épocas de florescimento disponíveis para o agricultor, para que o mesmo possa diversificar os genótipos a serem semeados, optando preferencialmente por semear cultivares tardias no inicio da safra e mais precoces no final da janela de semeadura. Diferentes ciclos de cultivares favorecem o escalonamento da colheita mecanizada, aumentando a eficiência de campo e favorecendo as operações [20].

$\mathrm{Na}$ avaliação do tamanho de panícula, ocorreu uma variação entre $16,04 \mathrm{~cm}$ e $38,65 \mathrm{~cm}$, sendo os híbridos 1167017,1170017 e 1169074 os que apresentaram o maior comprimento, e os híbridos 1168092, 1167092, 1168093, 1167093, 1099044 e 729033 os que apresentaram menor tamanho de panícula.

O comprimento de panícula é uma característica que vem acompanhada do número de grãos, consequentemente panículas maiores terão também um maior número de grãos, o que levará o híbrido a obter maior produtividade. De acordo com Avelino (2008)[1], a panícula, além de representar grande parte da matéria seca, contém grande valor nutricional devido a sua composição rica em carboidratos não estruturais.

Uma das características importantes na escolha de cultivares de sorgo granífero é o porte das plantas. Cultivares que apresentam menor altura de plantas, associada a maior resistência de colmo, apresentam menor suscetibilidade ao acamamento ou quebra das plantas [14]. De acordo com Santos (2003) [22], é interessante que cultivares de sorgo granífero apresentem altura entre 1 $\mathrm{m}$ e $1,5 \mathrm{~m}$.

Durante a condução do experimento não foi constatado nenhum problema com acamamento de plantas. Verificou-se que os híbridos mantiveram uma altura média de 1,33 m, não havendo diferença estatística entre os mesmos. A semelhança entre as alturas dos híbridos avaliados pode ser explicada pelo melhoramento genético realizado nos mesmos, tornando-os mais homogêneos e com altura média ideal para o cultivo na safrinha da região Centro-Oeste.

Silva et al. (2009) [14] avaliando cultivares de sorgo granífero na região centro-oeste verificaram diferença estatística entre os mesmos e com alturas variando de $0,71 \mathrm{~m}$ a $1,14 \mathrm{~m}$. As maiores alturas são atribuídas a maior disponibilidade de chuva durante o desenvolvimento do sorgo na região e as menores ao baixo índice pluviométrico durante o cultivo.

Para a característica peso de mil grãos, obteve-se média de 16,02 g com maiores pesos apresentados pelos híbridos DKB550, 1G244, 1237030, 1170017, 1167017 e 1099044. Os resultados obtidos são inferiores aos obtidos por Heckler (2002) [20] que obteve peso médio de mil grãos de 27,4 g avaliando diversas cultivares de sorgo cultivadas em Mato Grosso do Sul. Porém, os dados obtidos estão próximos aos obtidos por Silva et al. (2009) [14] que obtiveram média de 17,97 g em experimentos conduzidos no sudoeste goiano.

Os valores inferiores para o peso dos grãos pode ser atribuída a falta de água nos estádios de floração e de maturação da cultura conduzida no período da safrinha. De acordo com Magalhães et al. (2000)[11], o estresse hídrico pode acarretar perdas no incremento de produção. Destaca-se que os efeitos do estresse hídrico, nos componentes de rendimento de grãos do sorgo, são atribuídos a redução de área foliar e taxa fotossintética das plantas.

$\mathrm{O}$ rendimento médio foi de $3,78 \mathrm{t} \mathrm{ha}^{-1}$. Os resultados obtidos são considerados satisfatórios quando comparados a média regional de produção de sorgo na safra 2013/2014 que foi de 2,79 $\mathrm{t} \mathrm{ha}^{-1}$ [3]. A produtividade média da produção de sorgo no município de Jataí - GO situa-se em torno de $3,1 \mathrm{t} \mathrm{ha}^{-1}$ [2].

Os híbridos avaliados podem ser divididos em dois grupos em relação à produtividade, onde os híbridos mais produtivos foram 1238020, 1169092, 1G244, 843009, 1236020, 1099034, 1167053, BRS330, 1105661, 1099044, 1105653, 1167017, 729033 e 1167093 enquanto os híbridos 1237030, 1169074, 1096019, 1236011, 1168092, 1169054, 1170017, DKB550, 1167048,1167092 e 1168093 foram os menos produtivos. A produtividade média de grãos variou entre 2,28 e $4,47 \mathrm{t} \mathrm{ha}^{-1}$.

A maior produtividade alcançada pelos híbridos pode estar ligada tanto ao melhoramento genético dos mesmos quanto a maior adaptabilidade dos cultivares a região. Segundo Santos et al. (2005)[22], nas condições de safrinha e safra é possível obter produtividade de $7 \mathrm{t} \mathrm{ha}^{-1}$ e $10 \mathrm{t} \mathrm{ha}^{-1}$, respectivamente.

Em estudos avaliando cultivares de sorgo granífero em condições semiáridas, Albuquerque et al. (2011) [23] observaram produtividade de grãos variando entre 5,5 e 7,0 t ha ${ }^{-1}$ 
em um ano de elevados índices pluviométricos e, em um ano com baixa disponibilidade de chuvas, valores inferiores a $3,0 \mathrm{t} \mathrm{ha}^{-1}$.

Heckler (2002) [20] observou produtividade variando de 4,73 a 9,86 $\mathrm{t} \mathrm{ha}^{-1}$ avaliando 18 cultivares de sorgo granífero no Mato Grosso do Sul. Silva et al. (2009) [14] observaram a média geral de 2,81 t ha ${ }^{-1}$ avaliando cultivares em municípios do Sudoeste goiano, sendo que no município de Rio Verde obtiveram médias entre 0,64 a 1,69 t ha ${ }^{-1}$.

Tardin et al. (2012) [21], avaliando o rendimento de grãos de 25 híbridos de sorgo granífero em nove regiões brasileiras, obtiveram diferentes produtividades sendo que apenas um material testado apresentou produção superior à média nacional. Porém não alcançando a produtividade máxima a qual o sorgo tem potencial, isso pode ter se dado devido ao plantio tardio, o qual submeteu a cultura a um menor número de precipitações.

\section{CONCLUSÃO}

Não houve diferença estatística significativa para as características emborrachamento, florescimento e altura de plantas entre os híbridos avaliados.

Para tamanho de panículas os híbridos 1170017, 1169074 e 1167017 foram os que apresentaram maior comprimento.

Para peso de mil grãos os materiais que apresentaram maiores pesos foram: 1237030, 1170017, $1167017,1099044,1169074,1 G 244,1237030$ e DKB550.

Os híbridos que apresentaram maiores rendimentos foram: 1238020, 1169092, 1G244, 843009, 1236020, 1099034, 1167053, BRS330, 1105661, 1099044, 1105653, 1167017, 729033, 1167093.

\section{REFERÊNCIAS BIBLIOGRÁFICAS}

1. Avelino PM. Características produtivas e qualitativas de híbridos de sorgo (Sorghum bicolor L. Moench) para produção de silagem, cultivados sob diferentes densidades de plantio. [dissertação]. Araguaína[TO]: Universidade Federal do Tocantins; 2008. 56p.

2. Instituto Brasileiro de Geografia E Estatística. Produção agrícola municipal 2013. [Internet] Rio de Janeiro: IBGE; [citado em 2015 Mai 25]. Disponível em: ftp://ftp.ibge.gov.br/Producao_Agricola/Producao_Agricola_Municipal_\%5Banual\%5D/2013/pam2013 .pdf

3. Companhia Nacional de Abastecimento. Acompanhamento da safra brasileira: grãos safra 2014/2015 décimo primeiro levantamento. [Internet] Brasília: CONAB; [citado em 2015 Sep 25]. Disponível em: http://www.conab.gov.br/OlalaCMS/uploads/arquivos/15_08_18_10_30_18_boletim_graos_agosto_201 5.pdf

4. Gualtieri M, Rapaccini S. Sorghum grain in poultry feeding.World's Poultry Science Journal. 1990; 46 (3): 246-254.

5. Fialho ET, Lima JAF, Oliveira V, Silva HO. Corn substitution by sorghum without tannin in piglet rations: nutrient digestibility and animal performance. Revista Brasileira de Milho e Sorgo. 2002; 1(1): 105-111.

6. Brestenský M, Nitrayová S, Patráš P. The quality of sorghum grain in aspect of utilization amino acids in pigs. Journal of Microbiology, Biotechnology and Food Sciences. 2012; 1: 1032-1039.

7. Ruas DGG, Garcia JC, Teixeira NM. Origem e importância do sorgo para o Brasil. In: EMBRAPA. Centro Nacional de Pesquisa de Milho e Sorgo. Recomendações para o cultivo do sorgo. 3 ed. Sete Lagoas: EMBRAPA; 1988. p.7-11.

8. Tesini JR. Desempenho produtivo aos 21 dias de corte submetidos a dietas formuladas com grãos de sorgo de diferentes cultivares. [monografia]. Uberlândia(MG): Universidade Federal de Uberlândia, Uberlândia; 2003. 21p.

9. Mariguele KH, Silva PSL. Avaliação dos rendimentos de grãos e forragem de cultivares de sorgo granífero. Caatinga. 2002; 15(1/2): 13-18.

10. Coelho AM, Waquil JM, Karam D, Casela CR, Ribas PM. Seja o doutor do seu sorgo. Piracicaba: POTAFOS; 2002. 24p.

11. Magalhães PC, Durães FOM, Schaffert RE. Fisiologia da planta de sorgo. Sete Lagoas: Embrapa Milho e Sorgo; 2000. $46 \mathrm{p}$.

12. Pale S, Mason, SC, Galusha TD. Planting time for early-season pearl millet and grain sorghum in Nebraska. Agronomy Journal. 2003; 95 (4): 1047-1053. 
13. Souza CN, Souza IF, Pasqual M. Extração e ação do sorgoleone sobre o crescimento das plantas. Ciência e Agrotecnologia. 1999; 23 (2): 331-338.

14. Silva AG, Barros AS, Silva LHCP, Moraes EB, Pires R, Teixeira IR. Avaliação de cultivares de sorgo granífero na safrinha o sudoeste do estado de Goiás. Pesquisa Agropecuária Tropical. 2009; 39 (2): 168174.

15. Instituto Nacional de Meteorologia. BDMEP - Banco de Dados Meteorológicos para Ensino e Pesquisa: Série Histórica - Dados Diários de 01/01/1982 a 31/12/2012 Estação: 83464 - Jataí - GO. [Internet] Brasília: Ministério da Agricultura; [citado em 2014 Aug 11]. Disponível em: http://www.inmet.gov.br/portal/index.php?r=bdmep/bdmep

16. Instituto Nacional de Meteorologia. BDMEP - Banco de Dados Meteorológicos para Ensino e Pesquisa: Série Histórica - Dados Diários de 20/03/2014 a 11/06/2014 Estação: 83464 - Jataí - GO. [Internet] Brasília: Ministério da Agricultura; [citado em 2014 Aug 04]. Disponível em: http://www.inmet.gov.br/portal/index.php?r=bdmep/bdmep.

17. Empresa Brasileira de Pesquisa Agropecuária - EMBRAPA. Sistema brasileiro de classificação de solos. 3 ed. Rio de Janeiro: EMBRAPA/CNPSO, 2013. 353 p.

18. Belvilaqua LKA. Desempenho agronômico de híbridos de sorgo graníferoem Jataí-GO. [monografia]. Jataí (GO): Universidade Federal de Goiás; 2013. 15p.

19. Almeida Filho JE, Tardin FD, Daher RF, Silva KJ, Xavier Neto JB, Bastos E, Lopes VS, Barbé TC, Menezes CB. Avaliação agronômica de híbridos de sorgo granífero em diferentes regioões produtoras do Brasil.Revista Brasileira de Milho e Sorgo. 2014; 13 (1): 82-95.

20. Heckler JC. Sorgo e girassol no outono-inverno, em sistema plantio direto, no Mato Grosso do Sul, Brasil. Ciência Rural. 2002; 32 (3): 517-520.

21. Tardin FD, Almeida Filho JE, Daheer RF, Menezes CB, Silva KJ, Paula CM, Xavier Neto JB, Albuquerque CJB, Bastos EA, Cardoso MJ, Godinho VPC, Andrade FF, Lopes VS, Schaffert RE. Desempenho agronômico de híbridos de sorgo granífero cultivados em vários ambientes brasileiros. In. ABMS, editores. 2012: Anais do XXIX Congresso Nacional de Milho e Sorgo; 2012, Sete Lagoas: ABMS, 2012. p. 967-973.

22. Santos FG. Cultivares de Sorgo. Sete Lagoas: Embrapa Milho e Sorgo; 2003. 3 p.

23. Albuquerque CJB, Von Pinho RG, Rodrigues JAS, Brant RS, Mendes MC. Espaçamento e densidade de semeadura para cultivares de sorgo granífero no semiárido. Bragantia. 2011. 70 (2): 278-285. 